\title{
Patterns of the initiation of disease-modifying antirheumatic drugs in incident rheumatoid arthritis: a German perspective based on nationwide ambulatory drug prescription data
}

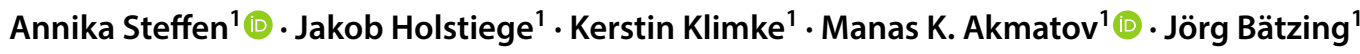

Received: 23 August 2018 / Accepted: 24 September 2018 / Published online: 10 October 2018

(c) The Author(s) 2018

\begin{abstract}
This study aimed at providing a current and nearly complete picture of the patterns of the initiation of disease-modifying antirheumatic drugs (DMARDs) in patients with newly diagnosed RA. Based on ambulatory drug prescription data and physician billing claims data covering $87 \%$ of the German population, we assembled a cohort of incident RA patients aged 15-79 years $(n=54,896)$ and assessed the prescription frequency of total DMARDs, conventional synthetic (csDMARDs) and biologic DMARDs (bDMARDs) within the first year of disease. Using multiple logistic regression, we estimated the chance of early DMARD receipt based on age, sex, serotype and specialty of prescribing physician while controlling for region of residence. In total, $44 \%$ of incident RA patients received a DMARD prescription within the first year of disease. In multiple regression, younger patients $(<35$ years) had 1.7 -fold higher chances of receiving a csDMARD than patients aged $\geq 65$ years [odds ratio (OR): 1.65 with $95 \%$ confidence interval (CI) 1.51-1.80] and almost tenfold higher chances to receive a bDMARD [OR (95\% CI) 9.5 (8.0-11.3)]. Seropositivity and a visit to a rheumatologist were positively associated with DMARD initiation [OR (95\% CI) 2.8 (2.6-2.9) and 5.9 (5.6-6.2) for csDMARDs, respectively]. Based on data covering $87 \%$ of the German population, the present study revealed that less than half of incident RA patients receive DMARDs within the first year of disease and that marked differences exist according to age. The study highlights the importance of involving a rheumatologist early in the management of RA.
\end{abstract}

Keywords Ambulatory drug prescription data $\cdot$ Biologicals $\cdot$ Disease-modifying antirheumatic drugs $\cdot$ Glucocorticoids . Non-steroidal anti-inflammatory drugs $\cdot$ Rheumatoid arthritis

Annika Steffen

asteffen@zi.de

Jakob Holstiege

jholstiege@zi.de

Kerstin Klimke

kklimke@zi.de

Manas K. Akmatov

makmatov@zi.de

Jörg Bätzing

jbaetzing@zi.de

1 Central Research Institute of Ambulatory Health Care in Germany (Zi), Salzufer 8, 10587 Berlin, Germany

\section{Background}

Rheumatoid arthritis (RA) is a chronic autoimmune disease characterized by inflammation of synovial tissues that leads to progressive, irreversible joint destruction, impaired joint function and pain [1]. It is one of the most prevalent chronic inflammatory diseases, affecting approximately $1 \%$ of the adult population in developed nations worldwide [2]. On the basis of nationwide claims data, we recently estimated the RA prevalence to be $1.2 \%$ in the adult population in Germany and the incidence amounting to 80 per 100,000 persons which corresponds to roughly 50,000 new cases in Germany per year [3]. On an individual level, RA is related to reduced quality of life and increased co-morbidity, including premature mortality [4]. On a societal level, RA imposes a high economic burden due to healthcare costs and work productivity loss. 
With the advent of highly effective medications, the management of RA has changed profoundly over the past 25 years [5]. RA management has evolved from a strategy of providing symptomatic relief to therapeutic regimens modifying disease activity, thereby preventing disease progression and joint destruction and improving health-related quality of life. Modern RA management focusses on early diagnosis, immediate initiation of effective therapy with disease-modifying antirheumatic drugs (DMARDs) and the requirement to set a therapeutic target ('treat-to-target strategy', T2T) [6-11]. Aggressive treatment during the early phase of RA has been shown to be more likely to succeed in preventing long-term sequelae and preserving functional status compared to the same treatment applied at later stages of the disease. This therapeutic 'window-of-opportunity' is widely accepted and refers to the timely initiation of DMARD therapy, ideally within the first 3 months of disease onset. Regular monitoring of the disease activity and adjustments of the therapy to the target of sustained remission (or low disease activity if remission is unattainable) are important aspects of the T2T strategy consistently embedded into national and international recommendations [6-11].

DMARDs, as the central component of every modern medication-based RA treatment regimen, are divided into two major classes: conventional synthetic (csDMARDs) and biologic DMARDs (bDMARDs). In addition, pharmacologic treatment of RA may include short-term glucocorticoids (GCs) as a bridging therapy [6] and non-steroidal anti-inflammatory drugs (NSAIDs) for pain relief.

Despite the importance of immediate DMARD therapy for virtually all patients with incident (active) RA, studies from the US, Canada and the UK suggest a considerable underuse of DMARDs among patients with newly diagnosed RA, indicating that only $50-60 \%$ of incident cases receive DMARDs within 1 year of diagnosis [12-14]. For Germany, it is currently unknown how well guideline recommendations are reflected in routine clinical care of the ambulatory setting. Although data on the treatment of RA patients within the specialty care of the German Collaborative Arthritis Centers do exist [15], data on the real-world treatment with DMARDs are limited to a study based on prevalent cases [16].

The present study offers the unique opportunity to describe real-world patterns of drug utilization in incident cases of RA covering $87 \%$ of the German population. The objective of the study was to provide a current and nearly complete picture of the population-based frequency of drug prescriptions (DMARDs, GCs, NSAIDs) in newly diagnosed cases of RA in the ambulatory setting in Germany over the first 3 years of the disease.

\section{Methods}

\section{Data source}

The present study is based on all ambulatory physician billing claims and pharmacologic treatments of residents with statutory health insurance (SHI) in Germany. Because roughly $87 \%$ of residents have SHI in Germany, the present analysis can be considered a nearly total coverage of the German population. In particular, two data sources were linked for the purpose of the current study. As first source, nationwide drug prescription data from the years 2009-2015 were used comprising all ambulatory drug prescriptions that were redeemed at pharmacies by SHIinsured persons. This dataset includes information on the prescribed medication, the patient (i.e. pseudonymized patient identifier and region of residence) and the prescribing physician. As second data source, we used ambulatory physician billing claims data from all 17 regional Associations of Statutory Health Insurance Physicians (ASHIPs), covering outpatient diagnoses of all SHI-insured residents treated in ambulatory care in Germany at least once in the years 2009-2015. The ASHIPs represent the interests of the SHI-authorized physicians in ambulatory care. They verify the invoices presented by the physicians and are responsible for reimbursement from the respective statutory sickness fund. The claims dataset contains information on the patient (i.e. pseudonymized patient identifier, sex, age, region of residence) and all diagnoses related to the patient. After linkage of the two datasets based on the patient information it was possible to analyse prescription patterns with respect to the indication RA.

\section{Study design and study population}

We designed a retrospective cohort study focusing on patients with newly diagnosed RA in 2012 and aged between 15 and 79 years. Figure 1 illustrates how the cohort of incident RA patients was derived from the cohort of patients with at least one physician contact in ambulatory care in $2012(n=61,781,599)$. RA patients were identified based on the diagnostic code (M05.-, M06.-) according to the ICD10-GM (International Statistical Classification of Diseases, German modification). Since diagnoses from ambulatory care include a diagnostic modifier describing the diagnostic certainty ("assured", "suspected", "status post", "excluded"), we restricted the analysis to diagnoses that included the diagnostic certainty "assured". A disease-free period of 3 years (2009-2011) was chosen to minimize bias due to inclusion of prevalent RA cases. Thus, incident cases of 
Fig. 1 Selection of the study population

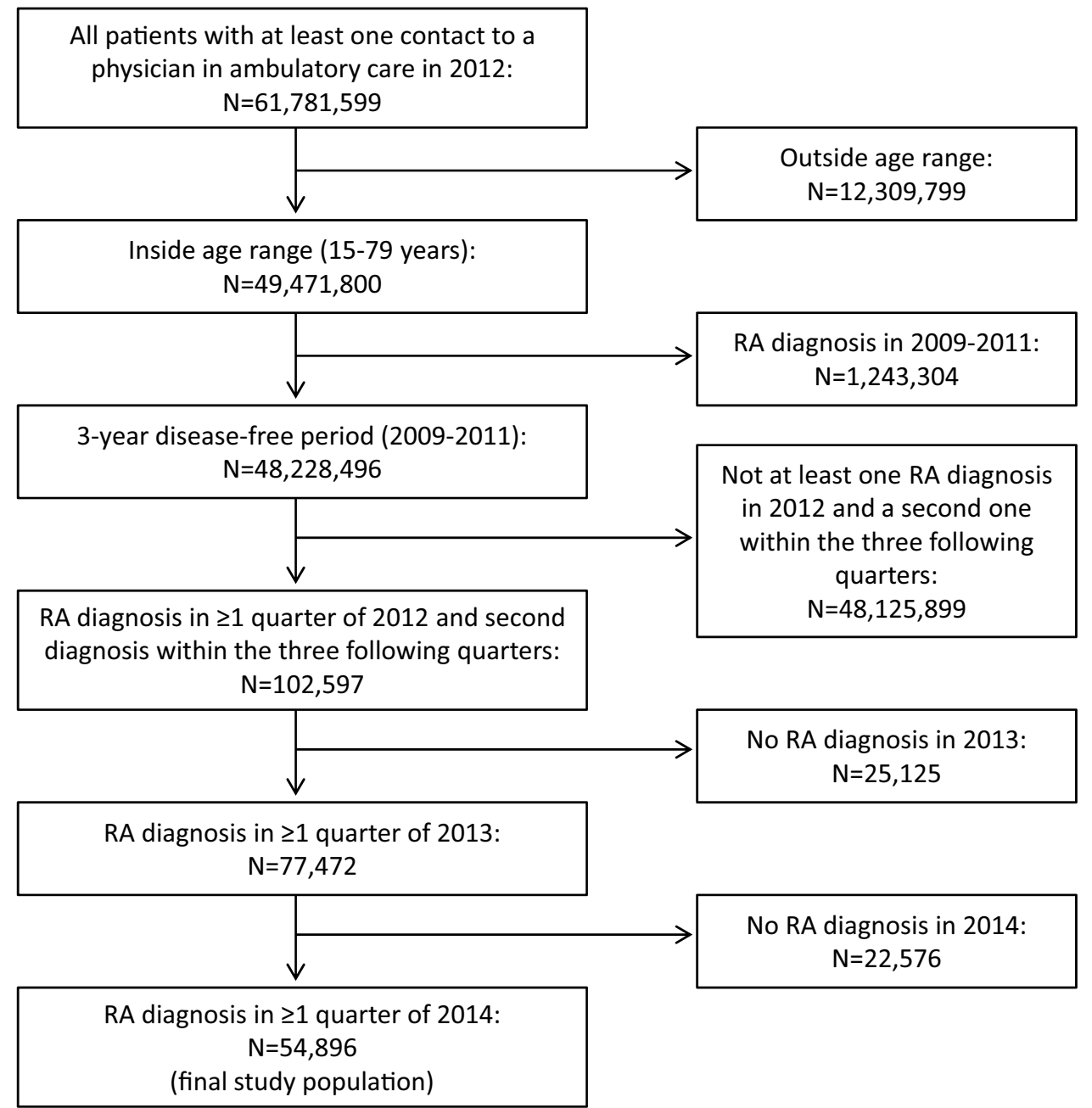

RA were defined as those patients who received their first diagnosis of RA in one quarter of the year 2012 (index quarter) and a second (confirmatory) diagnosis in one of the three quarters following the index quarter. In addition, we restricted the study population to only those patients who further had at least one RA diagnosis documented in 2013 and 2014, thereby focusing the analysis on RA patients who were in continuous ambulatory care for at least 3 years and reducing the likelihood of including false positives. The final study population comprised 54,896 patients with newly diagnosed RA in 2012 that were followed for 3 years from the index quarter.

\section{Medications of interest}

We included prescriptions for NSAIDs, GCs, csDMARDs and bDMARDs. Table 1 lists all included agents with their respective code according to the Anatomical Therapeutic Chemical (ATC) classification system.

\section{Statistical analysis}

Drug prescription patterns among incident RA patients were investigated within the first, second and third year after index diagnosis and combined for the first 3 years of disease. The prescription prevalence was determined as the percentage of incident RA patients who had been prescribed the included medication in the respective time period. Prescription prevalence was studied by sex, age ( $<35,35-<50,50-<65$ and $65-<80$ years), RA serotype [seropositive (M05) vs. seronegative (M06)] and across specialty groups of the prescribing physician. For the analysis according to serotype, patients were considered seropositive if they had received the diagnostic code M05 at least once within the first year of disease. 
Table 1 Substances and their ATC code included in the present study

\begin{tabular}{|c|c|}
\hline Substance & ATC code \\
\hline NSAIDs & M01A \\
\hline Glucocorticoids & H02AB \\
\hline \multicolumn{2}{|l|}{ csDMARDs } \\
\hline Auranofin & M01CB03 \\
\hline Chloroquine & P01BA01 \\
\hline Penicillamine & M01CC01 \\
\hline Hydroxychloroquine & P01BA02 \\
\hline Sulfasalazine & M01CX02 \\
\hline Azathioprine & L04AX01 \\
\hline Ciclosporin & L04AD01 \\
\hline Cyclophosphamide & L01AA01 \\
\hline Leflunomide & L04AA13 \\
\hline Methotrexate & $\begin{array}{l}\text { L01BA01, } \\
\text { L04AX03, } \\
\text { M01CX01 }\end{array}$ \\
\hline \multicolumn{2}{|l|}{ bDMARDs } \\
\hline Adalimumab & L04AB04 \\
\hline Certolizumab & L04AB05 \\
\hline Etanercept & L04AB01 \\
\hline Golimumab & L04AB06 \\
\hline Infliximab & L04AB02 \\
\hline Abatacept & L04AA24 \\
\hline Anakinra & L04AC03 \\
\hline Tocilizumab & L04AC07 \\
\hline Rituximab & L01XC02 \\
\hline
\end{tabular}

$A T C$ anatomic therapeutic chemical (ATC) classification system, NSAIDs non-steroidal anti-inflammatory drugs, csDMARDs conventional synthetic disease-modifying antirheumatic drugs, $b D M A R D s$ biologic disease-modifying antirheumatic drugs

All other patients were regarded as seronegative. With regard to physician specialty, patients were grouped into four categories: those who had received a prescription of the included medication by (a) exclusively general practitioners and general internists (in the following GP), (b) exclusively rheumatologists, (c) GP and rheumatologists, or by (d) other specialty groups.

Associations between selected characteristics and the chance of receiving a csDMARD, a bDMARD and a GC, respectively, within the first year of disease were analysed by estimating odds ratios (OR) and $95 \%$ confidence intervals $(95 \% \mathrm{CI})$ using logistic regression analysis. Each multivariable model included sex, age at diagnosis, RA serotype, specialty of the prescribing physician and residential region as independent variables. We also evaluated potential interaction between age and sex with regard to the chance of receiving csDMARDs, bDMARDs and GCs, respectively. $P$ values for all tests of interaction were based on the likelihood ratio test for the comparison of the multivariable model with interaction term to the multivariable model without interaction term. Since all $P$ values indicated significant interaction between age and sex (all $P<0.01$ ), we crossclassified patients according to sex and age group and estimated ORs with 95\% CIs for all subgroups in relation to women aged between 65 and $<80$ years (reference).

In sensitivity analysis, we repeated the main analysis on prescription prevalence after exclusion of patients who were not prescribed any medication within the first year of disease.

\section{Results}

We identified 54,896 patients with newly diagnosed RA in 2012 , of which about one-fifth (22\%) could be attributed to the seropositive type (Table 2). The majority of incident RA patients $(37,352[68 \%])$ were women and the mean $( \pm \mathrm{SD})$ age at diagnosis was $58.5(14.0)$ years. About three quarters (74\%) were 50 years and above. Half of the patients had received prescriptions only from a GP, 33\% had received prescriptions from a GP and a rheumatologist and 10\% had received prescriptions only from a rheumatologist.

Approximately $44 \%$ of the incident RA patients received a DMARD within the first year of RA disease (Table 2). Specifically, $41 \%$ received only a csDMARD, $2.1 \%$ received a csDMARD and a bDMARD and $1.2 \%$ received solely a bDMARD. A total of $3.3 \%$ was prescribed a bDMARD within the first year of disease. About $55 \%$ and $64 \%$ of patients received GCs and NSAIDs, respectively, in the first year of disease. Among those patients without DMARD prescription, the majority (70\%) was treated with GCs and/or NSAIDs (11\% received only GCs, 24\% NSAIDs and GCs, and $35 \%$ received only NSAIDs). With increasing duration of disease, the prescription prevalence of csDMARDs and GCs decreased, while bDMARDs were prescribed more frequently (Fig. 2). Within the first 3 years of RA disease, $64 \%$, $48 \%$ and $6.3 \%$ patients had received a prescription of GCs, csDMARDs and bDMARDs, respectively.

The prescription prevalence of all investigated medications was higher among males compared to females and varied according to age. Younger patients were more likely to receive DMARDs and less likely to receive GCs than their older counterparts. Specifically, $49 \%$ and $48 \%$ of patients aged $<35$ years received a csDMARD and a GC, respectively, while $40 \%$ and $60 \%$ of patients aged $\geq 65$ years were prescribed a csDMARD and a GC, respectively. The agerelated difference in prescription frequency was particularly pronounced for bDMARDs: while $10 \%$ of RA patients aged $<35$ years received bDMARDs, only $1.1 \%$ of those aged $\geq 65$ years received bDMARDs. The prescription prevalence of any DMARD was twofold higher in patients diagnosed with seropositive RA vs. patients diagnosed with seronegative RA (70\% vs. $37 \%$ ). Similarly, patients who had 
Table 2 Prescription prevalence of DMARDs, GCs and NSAIDs in patients with incident RA within the first year of diagnosis

\begin{tabular}{|c|c|c|c|c|c|c|c|c|}
\hline & \multirow[t]{3}{*}{$N$} & \multirow[t]{3}{*}{$(\%)$} & \multicolumn{6}{|c|}{ Within first year of disease } \\
\hline & & & \multicolumn{3}{|c|}{ DMARDs (\%) } & \multirow[t]{2}{*}{$\mathrm{GCs}(\%)$} & \multirow[t]{2}{*}{ NSAIDs $(\%)$} & \multirow{2}{*}{$\begin{array}{l}\text { Any } \\
\text { prescrip- } \\
\text { tion }\end{array}$} \\
\hline & & & All & csDMARDs & bDMARDs & & & \\
\hline Total & 54,896 & $(100)$ & 44.3 & 43.1 & 3.3 & 54.9 & 63.5 & 83.7 \\
\hline \multicolumn{9}{|l|}{ Sex } \\
\hline Men & 17,544 & $(32.0)$ & 46.9 & 45.3 & 4.1 & 58.0 & 64.2 & 85.0 \\
\hline Women & 37,352 & $(68.0)$ & 43.1 & 42.1 & 2.9 & 53.4 & 63.2 & 83.2 \\
\hline \multicolumn{9}{|l|}{ Age (years) } \\
\hline$<35$ & 3854 & (7.0) & 52.8 & 48.7 & 10.0 & 47.8 & 60.4 & 82.5 \\
\hline$\geq 35$ and $<50$ & 10,431 & $(19.0)$ & 47.5 & 45.6 & 5.1 & 51.0 & 65.8 & 83.8 \\
\hline$\geq 50$ and $<65$ & 20,536 & $(37.4)$ & 45.7 & 44.8 & 3.1 & 53.1 & 66.4 & 84.3 \\
\hline$\geq 65$ and $<80$ & 20,075 & $(36.6)$ & 39.5 & 39.1 & 1.1 & 60.1 & 60.1 & 83.5 \\
\hline \multicolumn{9}{|l|}{ Serotype } \\
\hline Seropositive & 12,161 & $(22.2)$ & 69.7 & 68.6 & 4.8 & 71.8 & 68.2 & 92.5 \\
\hline Seronegative & 42,735 & $(77.8)$ & 37.1 & 35.9 & 2.8 & 50.0 & 62.2 & 81.3 \\
\hline \multicolumn{9}{|c|}{ Specialty of prescribing physician ${ }^{a}$} \\
\hline Only GP & 23,081 & $(50.2)$ & 36.9 & 36.1 & 2.1 & 56.2 & 79.0 & 100 \\
\hline Only rheumatologist & 4726 & $(10.3)$ & 68.7 & 64.3 & 8.6 & 63.5 & 49.9 & 100 \\
\hline GP and rheumatologist & 14,985 & $(32.6)$ & 78.9 & 77.7 & 4.9 & 86.1 & 80.6 & 100 \\
\hline Other & 3182 & (6.9) & 23.4 & 20.7 & 4.7 & 39.3 & 69.8 & 100 \\
\hline
\end{tabular}

DMARDs disease-modifying antirheumatic drugs, $c s D M A R D s$ conventional synthetic DMARDs, bDMARDs biologic DMARDs, GCs glucocorticoids, NSAIDs non-steroidal anti-inflammatory drugs, GP general practitioner

${ }^{a}$ Only patients with any prescription within the first year of disease were included $(N=45,974)$

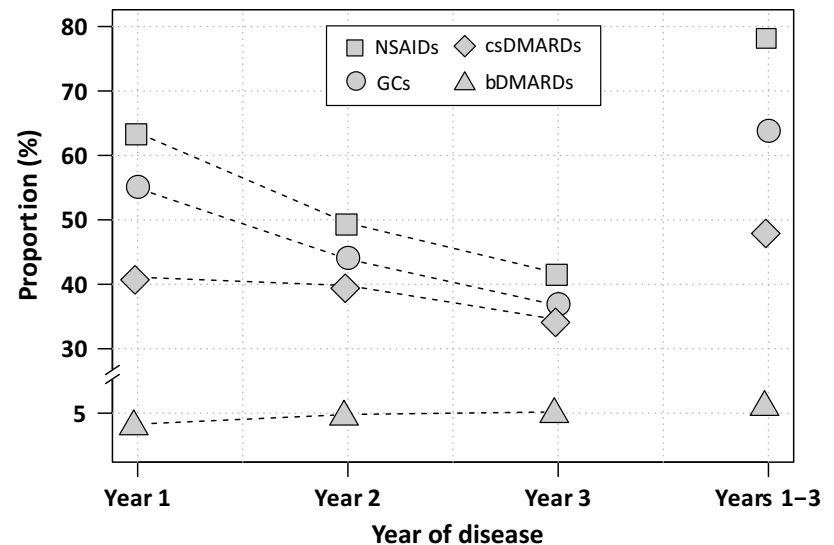

Fig. 2 Prescription prevalence of medications of interest within the first 3 years of RA disease. csDMARDs conventional synthetic disease-modifying antirheumatic drugs, $b D M A R D s$ biologic diseasemodifying antirheumatic drugs, GCs glucocorticoids, NSAIDs nonsteroidal anti-inflammatory drugs

received prescriptions from both, a GP and a rheumatologist, were twice as likely to receive DMARDs as patients who only had prescriptions from GP (79\% vs. 37\%).

All bivariate associations persisted in the multivariable logistic regression model (Table 3). Women had consistently and significantly lower odds of receiving a csDMARD, bDMARD and GC within the first year of disease compared to men. Specifically, the ORs $(95 \% \mathrm{CI})$ for women receiving prescriptions for csDMARDs, bDMARDs and GCs were $0.90(0.87-0.95), 0.62(0.57-0.69)$ and $0.88(0.84-0.92)$, respectively. Younger patients $(<35$ years) were $60 \%$ more likely to receive a csDMARD but $50 \%$ less likely to receive a GC within the first year of disease compared to their older counterparts ( $\geq 65$ years). With respect to bDMARDs, young patients had almost tenfold higher chances of receiving a prescription compared to patients aged $\geq 65$ years [OR $(95 \% \mathrm{CI})=9.5(8.0-11.3)]$. The cross-classification of sex and age group resulted in a differentiated picture on the interaction between sex and age with regard to the receipt of csDMARDs, bDMARDs and GCs (Fig. 3a-c). In terms of csDMARDs, the association of age differed noticeably between sexes (Fig. 3a). While among men, the chances of receiving a csDMARD did not differ between patients up to the age of 65 , among women a strong linear inverse association across age groups was observed, demonstrating that the lower odds observed for the group of all women in the multiple logistic regression model as described above was driven by the middle-aged and older women (50- $<65$ years and $\geq 65$ years). Young women $(<35$ years) had the highest chances of early csDMARD receipt compared to all cross-classified 
Table 3 Multivariable-adjusted odds ratio $(95 \% \mathrm{CI})$ for the association of demographics, RA serotype and prescribing physician with prescriptions of DMARDs and GCs within the first year of disease

\begin{tabular}{llll}
\hline & csDMARDs & bDMARDs & Glucocorticoids \\
\hline $\begin{array}{l}\text { Women vs. men } \\
\text { Age (years) }\end{array}$ & $0.90(0.87-0.95)$ & $0.62(0.57-0.69)$ & $0.88(0.84-0.92)$ \\
$\quad<35$ & $1.65(1.51-1.80)$ & $9.5(8.0-11.3)$ & $0.48(0.44-0.52)$ \\
$\geq 35$ and $<50$ & $1.34(1.27-1.43)$ & $4.56(3.89-5.34)$ & $0.56(0.52-0.59)$ \\
$\geq 50$ and $<65$ & $1.29(1.23-1.36)$ & $2.71(2.34-3.16)$ & $0.61(0.59-0.64)$ \\
$\geq 65$ and $<80$ (Ref.) & 1.00 & 1.00 & 1.00 \\
Seropositive vs. seronegative & $2.77(2.63-2.91)$ & $1.32(1.18-1.46)$ & $1.70(1.60-1.80)$ \\
Specialty of prescribing physician & & & \\
Only GP (ref.) & 1.00 & 1.00 & 1.00 \\
Only rheumatologist & $3.12(2.91-3.33)$ & $3.83(3.33-4.41)$ & $1.45(1.36-1.55)$ \\
GP and rheumatologist & $5.89(5.61-6.19)$ & $2.24(1.99-2.53)$ & $4.77(4.52-5.04)$ \\
Other & $0.43(0.39-0.47)$ & $2.04(1.68-2.47)$ & $0.53(0.49-0.57)$ \\
\hline
\end{tabular}

Estimates of effect originate from three separate logistic regression models containing all listed variables and additional adjustment for residential region. Only patients with any prescription within the first year of disease were included $(N=45,974)$

DMARDs disease-modifying antirheumatic drugs, cSDMARDs conventional synthetic DMARDs, bDMARDs biologic DMARDs, GCs glucocorticoids, GP general practitioner subgroups [OR $(95 \% \mathrm{CI})=1.78(1.61-1.97)]$. With regard to bDMARDs, we observed a strong inverse association with age, both among men and women, though men had significantly higher chances of receiving bDMARDs up to age of 65 years compared to women (Fig. 3b). With regard to GCs, differences in the chance of a prescription were less pronounced between men and women below the age of 65 , while older men were $35 \%$ more like to receive GCs than women at the same age [OR $(95 \% \mathrm{CI})=1.35(1.25-1.46)]$.

In $71 \%$ of the cases, the initial DMARD prescribed was methotrexate, followed by sulfasalazine (12\%) and hydroxychloroquine $(8 \%)$. In $5.6 \%$ of the cases, more than one DMARD was prescribed in the quarter of the index diagnosis, mainly including other csDMARDs in addition to methotrexate. The most important bDMARDs as initial agents were adalimumab (2.1\%) and etanercept (1.6\%). In terms of the whole first year of disease, $75 \%$ of incident patients who had been prescribed a DMARD received methotrexate, $14 \%$ sulfasalazine, $11 \%$ leflunomid and $10 \%$ hydroxychloroquine.

After excluding patients who did not receive any medication during the first year of disease, the prescription prevalence of total DMARDs, csDMARDs, bDMARDs, GCs and NSAIDS was $53 \%, 52 \%, 3.9 \%, 66 \%$ and $77 \%$, respectively.

\section{Discussion}

In a real-world setting comprising data of $87 \%$ of the German population, we evaluated patterns of drug prescriptions among patients with newly diagnosed RA in ambulatory care. The present study thereby adds to the latest knowledge on how guideline recommendations on DMARD treatment in newly diagnosed RA have been translated into actual clinical practice in Germany. Less than half of the incident RA cases received a DMARD within the first year of disease and substantial differences were observed according to age, sex, RA serotype and specialty of prescribing physician.

It is undoubted that the appropriate and timely use of DMARDs can improve clinical and long-term outcomes in RA [17, 18]. Hence, the importance of initiating DMARD therapy as soon as possible after diagnosis of RA is consistently emphasized as the mainstay of modern RA management in national and international guidelines $[6,7,9-11$, 19]. Our observation indicates that a substantial proportion of patients do not receive DMARDs within the first year of disease suggesting a general underuse of DMARDs in treatment of newly diagnosed RA. Reasons underlying this observation remain unresolved so far but may comprise (a) contraindications to DMARD therapy, (b) a very mild course of the disease initially not requiring DMARD treatment and (c) doctors' or patient attitudes. In case of mild disease, low disease activity and no indication of progression, patients may initially refrain from DMARD therapy according to guidelines [20]. In line with this, we found that the majority of patients without DMARD use were treated with GCs and/or NSAIDs. Bukhari et al. observed that roughly $30 \%$ of RA patients have a mild disease course with hardly any progression in radiographic outcome over 5 years [21]. Further, the attitudes of doctors' and patients' towards aggressive therapy, potential side-effects and route of administration may impact utilization of DMARDs [1, 22].

Most strikingly, we observed considerable disparities in the initiation of DMARD therapy across patient subgroups implying an inequitable access among patients with newly diagnosed RA. The German health care system is committed 

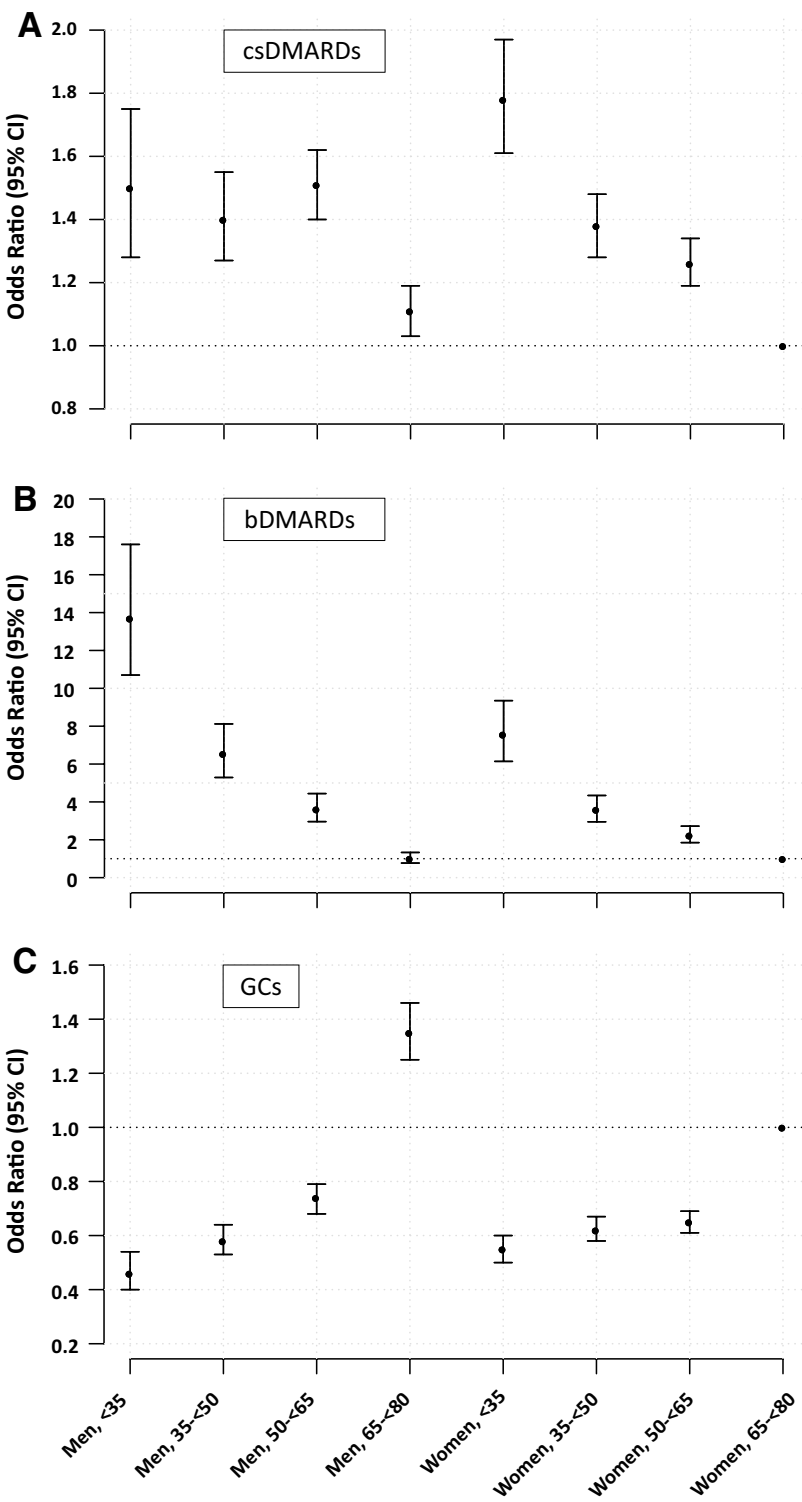

Fig. 3 Multivariable-adjusted Odds Ratio (95\% CI) for the chance of receiving csDMARDs (a), bDMARDs (b) and GCs (c) within the first year of disease according to sex and age group with women aged between 65 and $<80$ as reference. Estimates of effect originate from three separate logistic regression models containing groups of age and sex and adjustment for serotype, specialty of prescribing physician and residential region. Only patients with any prescription within the first year of disease were included $(N=45,974)$. csDMARDs conventional synthetic DMARDs, $b D M A R D s$ biologic DMARDs, GCs glucocorticoids

to providing universal and equitable access to high-quality medical services for all residents. Therefore, medical treatment would be primarily driven by need factors while predisposing factors, including age and sex, or enabling factors (i.e. visit to a rheumatologist) should not determine access to treatment.
In the present study, women generally had lower chances of receiving DMARDs and GCs compared to men. This observation was almost consistently present across all age groups, suggesting that women may be systematically disadvantaged with regard to early initiation of adequate RA therapy. In terms of csDMARDs, we demonstrated a complex interplay of sex with age and identified old women (aged $\geq 65$ years) as the most vulnerable patient group with the lowest chance of receiving a csDMARD compared to all other subgroups of age and sex. Conversely, young women had the highest chance of being prescribed a csDMARD, highlighting considerable inequities within the group of women. To our knowledge, a differential effect of age among men and women has not been described before and reasons for this finding remain to be elucidated. There is evidence to suggest that women's access to adequate RA therapy may have improved during the first decade of the twenty-first century [23]. The authors of a Norwegian study hypothesized that this may be due to the increased women's ability to communicate RA-related limitations and needs as a result of continuously disappearing gender differences in society within recent decades. Since we did not observe a differential association between sex and chance of csDMARD therapy among patients younger than 50 years, the finding that women aged $\geq 50$ years were disadvantaged could, therefore, at least partly, reflect traditional gender role attitudes and may essentially represent a cohort effect. Given that Germany lags behind Norway with regard to equality of sexes, the observed sex difference might continuously decrease over the next years. Nonetheless, future research may undertake efforts to elucidate gender differences in uptake of drugs in RA therapy.

With regard to age, our study suggests a preferential treatment of older RA patients with glucocorticoids rather than DMARDs. Discrepancies in receipt of DMARDs according to age have already been observed in earlier population-based studies [16, 24-30], though reasons for this age-related variation are currently unknown. Tutuncu et al. reported this age difference to be independent of duration, severity and activity of the disease [27]. A survey among US rheumatologists revealed that rheumatologists' treatment recommendations may be influenced by the patient's age with a preference for aggressive treatment among younger compared to older patients given the same disease activity and comorbidities [31]. Concerns regarding a differential toxicity of drugs among older persons, including a higher risk for infections, or patient-related factors such as lower health literacy, comorbidities, contraindications and fear of initially trying an "aggressive" treatment with potentially considerable side effects may partly explain the differential prescribing of DMARDs according to age [27, 30, 32]. However, with regard to bDMARDs, inequalities by age remained unchanged after controlling for the number of comorbidities 
in a Norwegian study [30]. Given that more than one-third of RA patients is diagnosed at $\geq 65$ years of age and studies generally show older age at onset to be related to higher disease activity [33], future studies may further examine the factors influencing the choice of pharmacotherapy in older persons with new-onset RA in more detail, also with focus on gender differences. In addition, efforts to increase the physicians' awareness of this potential age bias in RA treatment may be useful to ensure equal health care delivery across age. Furthermore, research in accurate RA medication in the context of multi-morbidity and polypharmacy, especially in the elderly, should be addressed and translated into future guidelines.

The present study emphasizes the key role of rheumatologists for the appropriate care of RA, which is in line with previous studies [12, 16, 34]. It is noteworthy though, that only $43 \%$ of incident RA patients in this large populationbased dataset had contact with a rheumatologist based on the receipt of a prescription within the first year of disease. This finding is consistent with the recent study of Albrecht et al. who found that $40 \%$ of the prevalent cases identified based on claims data from a German statutory health insurance fund had at least one contact with a rheumatologist in the ambulatory setting within the study period of 1 year [16]. In reality, the proportion of patients seen by a rheumatologist may be a little higher since we were not able to identify those additional patients with ambulatory treatments in specialty care conducted in university ambulances and by rheumatologists working as general practitioners. Based on data from the German Collaborative Arthritis Centers and results from a small population survey involving RA patients, it is assumed that about $60 \%$ of patients are in rheumatological specialty care in Germany [35, 36]. Considering the differential prescription prevalence according to specialty of the physician, an improved rapid referral to rheumatologists indicates a considerable potential for optimizing care of RA patients. However, to cover the corresponding demand the German Society for Rheumatology recently estimated that twice as many rheumatologists would be needed for ambulatory specialty care as currently exist [37].

We further found an almost threefold higher chance of receiving a csDMARD within the first year of disease in seropositive compared to seronegative patients, which was independent of age, sex, specialty of the prescribing physician and region of residence. Similarly, in a French multicenter cohort study, the presence of seropositivity was related to higher conformity to treatment guidelines in the multivariable analysis in comparison to seronegativity [38]. Since the presence of seropositivity is generally related to more severe symptoms and joint damage [1], a more intense treatment in seropositive patients would be expected. Nevertheless, a German population survey reported considerable deficits in the treatment of seronegative patients upon clinical examination [36]. In that study, $46 \%$ of seronegative cases were considered to be insufficiently treated. Likewise, in the German Collaborative Arthritis Centers, seronegative patients frequently report an impaired quality of life and often receive analgesics [15]. Thus, an unmet need for DMARDs may exist in this subgroup and further studies may focus on reasons for these marked differences in treatment according to serotype.

Among the strengths of the present study are the reallife setting and the large sample size covering $87 \%$ of the German population. In addition, these data allowed for the complete ascertainment of dispensed ambulatory prescriptions of DMARDs in an unselected population. Finally, the length of the study period (2009-2015) allowed for a rigorous case definition including a disease-free period of 3 years and a 2-year confirmation period with continuous documentation of RA diagnosis. Limitations of our study refer to the commonly recognized constraints of administrative claims data. First, the inclusion of patients was based on the presence of specific diagnostic codes and was, therefore, dependent on the accuracy of these codes. We addressed this limitation by applying a strict case definition requiring documentation of RA diagnosis in several years to ensure a high specificity. Misdiagnosis of RA may exist particularly in the early stages of the disease and we cannot entirely rule out that some of the included patients actually do not have RA. Including false positive cases in our analysis would have resulted in a lower prescription prevalence than actually present. Nevertheless, the prescription frequency of DMARDs increased only moderately when we restricted the study population to patients with at least one dispensed prescription within the first year of disease, still implying a considerable underuse. Second, administrative claims data do not allow determining disease activity/severity which, however, is central to therapeutic decisions in RA. The lack of this information has to be kept in mind when interpreting our results as real-world evidence of the adoption of clinical treatment recommendations. Third, although we tried to account for confounding factors in the multivariable regression model, we were not able to account for variables not available in the administrative data base, including socioeconomic status, smoking and clinical parameters, which may be related to the initiation of DMARDs. Fourth, since our data were limited to drugs that were redeemed at pharmacies, we may underestimate the use of NSAIDs which are frequently purchased directly over-the-counter. Finally, our analysis was restricted to prescriptions from ambulatory care and did not include medications administered in hospitals. Despite that, it is unlikely that we underestimated prescription prevalence of DMARDs since patients are only treated in hospital for a short time period and any 
DMARD therapy that is initiated in hospital will be continued in ambulatory care and thus included in the present dataset.

\section{Conclusion}

Despite disease modification is the mainstay of modern RA treatment, this nationwide population-based study revealed that in the majority of patients DMARD therapy is not initiated within the first year of disease. This suggests that further efforts may be needed to ensure full implementation of recommendations in clinical practice. Specialized rheumatology care emerged as a key factor for adequate treatment. Our study further identified older and seronegative patients as particularly vulnerable groups with lower likelihood of receiving DMARDs. Future studies may investigate the factors underlying these inequalities in DMARD prescriptions.

Funding None.

\section{Compliance with ethical standards}

Conflict of interest AS declares that she has no conflict of interest. JH declares that he has no conflict of interest. KK declares that she has no conflict of interest. MKA declares that he has no conflict of interest. JB declares that he has no conflict of interest.

Ethical approval This article does not contain any studies with human participants performed by any of the authors. This study was exempted from institutional review board oversight and informed consent since only anonymized data were analysed in accordance with $\S 300$ paragraph 2 Volume V of the Social Security Code (Sozialgesetzbuch (SGB) V).

Open Access This article is distributed under the terms of the Creative Commons Attribution 4.0 International License (http://creativeco mmons.org/licenses/by/4.0/), which permits unrestricted use, distribution, and reproduction in any medium, provided you give appropriate credit to the original author(s) and the source, provide a link to the Creative Commons license, and indicate if changes were made.

\section{References}

1. Smolen JS, Aletaha D, McInnes IB (2016) Rheumatoid arthritis. Lancet 388(10055):2023-2038. https://doi.org/10.1016/S0140 $-6736(16) 30173-8$

2. Gibofsky A (2012) Overview of epidemiology, pathophysiology, and diagnosis of rheumatoid arthritis. Am J Manag Care 18(13 Suppl):S295-S302

3. Steffen A, Holstiege J, Goffrier B, Bätzing J (2017) Epidemiology of rheumatoid arthritis in Germany-an analysis based on nationwide claims data of outpatient care. Central Research Institute of Ambulatory Health Care in Germany. https://www.versorgung satlas.de/fileadmin/ziva_docs/85/VA-85-RheumatoideArthritis -Abstract-English.pdf. Accessed 20 Apr 2018
4. Dadoun S, Zeboulon-Ktorza N, Combescure C, Elhai M, Rozenberg S, Gossec L, Fautrel B (2013) Mortality in rheumatoid arthritis over the last fifty years: systematic review and meta-analysis. Jt Bone Spine 80(1):29-33. https://doi.org/10.1016/j.jbspin.2012.02.005

5. Upchurch KS, Kay J (2012) Evolution of treatment for rheumatoid arthritis. Rheumatology (Oxford) 51(Suppl 6):28-36. https://doi. org/10.1093/rheumatology/kes278

6. Smolen JS, Landewé R, Bijlsma J, Burmester G, Chatzidionysiou K, Dougados M, Nam J, Ramiro S, Voshaar M, van Vollenhoven R, Aletaha D, Aringer M, Boers M, Buckley CD, Buttgereit F, Bykerk V, Cardiel M, Combe B, Cutolo M, van Eijk-Hustings Y, Emery P, Finckh A, Gabay C, Gomez-Reino J, Gossec L, Gottenberg J-E, Hazes JMW, Huizinga T, Jani M, Karateev D, Kouloumas M, Kvien T, Li Z, Mariette X, McInnes I, Mysler E, Nash P, Pavelka K, Poór G, Richez C, van Riel P, Rubbert-Roth A, Saag K, da Silva J, Stamm T, Takeuchi T, Westhovens R, de Wit M, van der Heijde D (2017) EULAR recommendations for the management of rheumatoid arthritis with synthetic and biological disease-modifying antirheumatic drugs: 2016 update. Ann Rheum Dis 76(6):960-977. https://doi.org/10.1136/annrheumdis-2016-210715

7. Smolen JS, Landewé R, Breedveld FC, Dougados M, Emery P, Gaujoux-Viala C, Gorter S, Knevel R, Nam J, Schoels M, Aletaha D, Buch M, Gossec L, Huizinga T, Bijlsma JWJW, Burmester G, Combe B, Cutolo M, Gabay C, Gomez-Reino J, Kouloumas M, Kvien TK, Martin-Mola E, McInnes I, Pavelka K, van Riel P, Scholte M, Scott DL, Sokka T, Valesini G, van Vollenhoven R, Winthrop KL, Wong J, Zink A, van der Heijde D (2010) EULAR recommendations for the management of rheumatoid arthritis with synthetic and biological disease-modifying antirheumatic drugs. Ann Rheum Dis 69(6):964-975. https://doi.org/10.1136/ ard.2009.126532

8. Saag KG, Teng GG, Patkar NM, Anuntiyo J, Finney C, Curtis JR, Paulus HE, Mudano A, Pisu M, Elkins-Melton M, Outman R, Allison JJ, Suarez Almazor M, Bridges SL, Chatham WW, Hochberg M, MacLean C, Mikuls T, Moreland LW, O’Dell J, Turkiewicz AM, Furst DE, American College of R (2008) American College of Rheumatology 2008 recommendations for the use of nonbiologic and biologic disease-modifying antirheumatic drugs in rheumatoid arthritis. Arthritis Rheum 59(6):762-784. https:// doi.org/10.1002/art.23721

9. Singh JA, Furst DE, Bharat A, Curtis JR, Kavanaugh AF, Kremer JM, Moreland LW, O'Dell J, Winthrop KL, Beukelman T, Bridges SL, Chatham WW, Paulus HE, Suarez-Almazor M, Bombardier C, Dougados M, Khanna D, King CM, Leong AL, Matteson EL, Schousboe JT, Moynihan E, Kolba KS, Jain A, Volkmann ER, Agrawal H, Bae S, Mudano AS, Patkar NM, Saag KG (2012) 2012 update of the 2008 American College of Rheumatology recommendations for the use of disease-modifying antirheumatic drugs and biologic agents in the treatment of rheumatoid arthritis. Arthritis Care Res (Hoboken) 64(5):625-639. https:// doi.org/10.1002/acr.21641

10. Singh JA, Saag KG, Bridges SL, Akl EA, Bannuru RR, Sullivan MC, Vaysbrot E, McNaughton C, Osani M, Shmerling RH, Curtis JR, Furst DE, Parks D, Kavanaugh A, O’Dell J, King C, Leong A, Matteson EL, Schousboe JT, Drevlow B, Ginsberg S, Grober J, St Clair EW, Tindall E, Miller AS, McAlindon T, American College of R (2016) 2015 American College of Rheumatology guideline for the treatment of rheumatoid arthritis. Arthritis Care Res (Hoboken) 68(1):1-25. https://doi.org/10.1002/acr.22783

11. Wollenhaupt J, Albrecht K, Krüger K, Müller-Ladner U (2013) The new 2012 German recommendations for treating rheumatoid arthritis: differences compared to the European standpoint. Z Rheumatol 72(1):6-9. https://doi.org/10.1007/s00393-012-1093-6

12. Widdifield J, Bernatsky S, Paterson JM, Thorne JC, Cividino A, Pope J, Gunraj N, Bombardier C (2011) Quality care in seniors with new-onset rheumatoid arthritis: a Canadian 
perspective. Arthritis Care Res (Hoboken) 63(1):53-57. https:// doi.org/10.1002/acr.20304

13. Bonafede MMK, Fox KM, Johnson BH, Watson C, Gandra SR (2012) Factors associated with the initiation of disease-modifying antirheumatic drugs in newly diagnosed rheumatoid arthritis: a retrospective claims database study. Clin Ther 34(2):457-467. https://doi.org/10.1016/j.clinthera.2011.12.016

14. Edwards CJ, Campbell J, van Staa T, Arden NK (2012) Regional and temporal variation in the treatment of rheumatoid arthritis across the UK: a descriptive register-based cohort study. BMJ Open 2(6):e001603. https://doi.org/10.1136/bmjopen-2012-001603

15. Albrecht K, Huscher D, Eidner T, Kleinert S, SpäthlingMestekemper S, Bischoff S, Zink A (2017) Medical treatment of rheumatoid arthritis in 2014: current data from the German Collaborative Arthritis Centers. Z Rheumatol 76(1):50-57. https ://doi.org/10.1007/s00393-016-0156-5

16. Albrecht K, Luque Ramos A, Callhoff J, Hoffmann F, Minden K, Zink A (2018) Outpatient care and disease burden of rheumatoid arthritis: results of a linkage of claims data and a survey of insured persons. Z Rheumatol 77(2):102-112. https://doi.org/10.1007/ s00393-017-0294-4

17. Solomon DH, Bitton A, Katz JN, Radner H, Brown EM, Fraenkel L (2014) Review: treat to target in rheumatoid arthritis: fact, fiction, or hypothesis? Arthritis Rheumatol 66(4):775-782. https:// doi.org/10.1002/art.38323

18. Stoffer MA, Schoels MM, Smolen JS, Aletaha D, Breedveld FC, Burmester G, Bykerk V, Dougados M, Emery P, Haraoui B, Gomez-Reino J, Kvien TK, Nash P, Navarro-Compán V, Scholte-Voshaar M, van Vollenhoven R, van der Heijde D, Stamm TA (2016) Evidence for treating rheumatoid arthritis to target: results of a systematic literature search update. Ann Rheum Dis 75(1):16-22. https://doi.org/10.1136/annrheumdis-2015-207526

19. Smolen JS, Aletaha D, Bijlsma JWJ, Breedveld FC, Boumpas D, Burmester G, Combe B, Cutolo M, de Wit M, Dougados M, Emery P, Gibofsky A, Gomez-Reino JJ, Haraoui B, Kalden J, Keystone EC, Kvien TK, McInnes I, Martin-Mola E, Montecucco C, Schoels M, van der Heijde D, van der Heijde D, Committee TTE (2010) Treating rheumatoid arthritis to target: recommendations of an international task force. Ann Rheum Dis 69(4):631637. https://doi.org/10.1136/ard.2009.123919

20. Deutsche Gesellschaft für Rheumatologie (2012) S1-Leitlinie der Deutschen Gesellschaft für Rheumatologie: Handlungsempfehlungen der DGRh zur sequenziellen medikamentösen Therapie der rheumatoiden Arthritis 2012: adaptierte EULAR Empfehlungen und aktualisierter Therapiealgorithmus. https://dgrh.de/dam/ jcr:f887ba34-f7fc-4a6f-bf55-dde42aacb25c/leitlinie_s1_medik amentoese_therapie_ra.pdf. Accessed 20 Apr 2018

21. Bukhari MaS, Wiles NJ, Lunt M, Harrison BJ, Scott DGI, Symmons DPM, Silman AJ (2003) Influence of disease-modifying therapy on radiographic outcome in inflammatory polyarthritis at five years: results from a large observational inception study. Arthritis Rheum 48(1):46-53. https://doi.org/10.1002/art.10727

22. Louder AM, Singh A, Saverno K, Cappelleri JC, Aten AJ, Koenig AS, Pasquale MK (2016) Patient preferences regarding rheumatoid arthritis therapies: a conjoint analysis. Am Health Drug Benefits 9(2):84-93

23. Putrik P, Ramiro S, Kvien TK, Sokka T, Pavlova M, Uhlig T, Boonen A, Working Group 'Equity in access to treatment of rheumatoid arthritis in E (2014) Inequities in access to biologic and synthetic DMARDs across 46 European countries. Ann Rheum Dis 73 (1):198-206. https://doi.org/10.1136/annrheumdis-2012-202603

24. Schmajuk G, Trivedi AN, Solomon DH, Yelin E, Trupin L, Chakravarty EF, Yazdany J (2011) Receipt of disease-modifying antirheumatic drugs among patients with rheumatoid arthritis in Medicare managed care plans. JAMA 305(5):480-486. https:// doi.org/10.1001/jama.2011.67
25. Kim G, Barner JC, Rascati K, Richards K (2015) Factors associated with the initiation of biologic disease-modifying antirheumatic drugs in Texas Medicaid patients with rheumatoid arthritis. J Manag Care Spec Pharm 21(5):401-407. https://doi. org/10.18553/jmcp.2015.21.5.401

26. Lacaille D, Anis AH, Guh DP, Esdaile JM (2005) Gaps in care for rheumatoid arthritis: a population study. Arthritis Rheum 53(2):241-248. https://doi.org/10.1002/art.21077

27. Tutuncu Z, Reed G, Kremer J, Kavanaugh A (2006) Do patients with older-onset rheumatoid arthritis receive less aggressive treatment? Ann Rheum Dis 65(9):1226-1229. https://doi.org/10.1136/ ard.2005.051144

28. Huscher D, Mittendorf T, von Hinüber U, Kötter I, Hoese G, Pfäfflin A, Bischoff S, Zink A, German Collaborative Arthritis C (2015) Evolution of cost structures in rheumatoid arthritis over the past decade. Ann Rheum Dis 74(4):738-745. https://doi. org/10.1136/annrheumdis-2013-204311

29. Desai RJ, Rao JK, Hansen RA, Fang G, Maciejewski ML, Farley JF (2014) Predictors of treatment initiation with tumor necrosis factor- $\alpha$ inhibitors in patients with rheumatoid arthritis. J Manag Care Spec Pharm 20(11):1110-1120. https://doi.org/10.18553/ jmcp.2014.20.11.1110

30. Putrik P, Ramiro S, Lie E, Keszei AP, Kvien TK, van der Heijde D, Landewe R, Uhlig T, Boonen A (2016) Less educated and older patients have reduced access to biologic DMARDs even in a country with highly developed social welfare (Norway): results from Norwegian cohort study NOR-DMARD. Rheumatology 55(7):1217-1224. https://doi.org/10.1093/rheumatology/kew048

31. Fraenkel L, Rabidou N, Dhar R (2006) Are rheumatologists' treatment decisions influenced by patients' age? Rheumatology 45(12):1555-1557. https://doi.org/10.1093/rheumatology/kel144

32. Chilton F, Collett RA (2008) Treatment choices, preferences and decision-making by patients with rheumatoid arthritis. Musculoskeletal Care 6(1):1-14. https://doi.org/10.1002/msc.110

33. Arnold MB, Bykerk VP, Boire G, Haraoui BP, Hitchon C, Thorne C, Keystone EC, Pope JE, Investigators C (2014) Are there differences between young- and older-onset early inflammatory arthritis and do these impact outcomes? An analysis from the CATCH cohort. Rheumatology 53(6):1075-1086. https://doi.org/10.1093/rheumatolo gy/ket 449

34. Solomon DH, Ayanian JZ, Yelin E, Shaykevich T, Brookhart MA, Katz JN (2012) Use of disease-modifying medications for rheumatoid arthritis by race and ethnicity in the National Ambulatory Medical Care Survey. Arthritis Care Res (Hoboken) 64(2):184189. https://doi.org/10.1002/acr.20674

35. Zink A (2014) Versorgungsforschung in der RheumatologieAktueller Stand. Z Rheumatol 2(73):115-122. https://doi. org/10.1007/s00393-013-1258-y

36. Westhoff G, Schneider M, Raspe H, Zeidler H, Runge C, Volmer T, Zink A (2009) Advance and unmet need of health care for patients with rheumatoid arthritis in the German populationresults from the German Rheumatoid Arthritis Population Survey (GRAPS). Rheumatology 48(6):650-657. https://doi.org/10.1093/ rheumatology/kep045

37. Zink A, Braun J, Gromnica-Ihle E, Krause D, Lakomek HJ, Mau W, Müller-Ladner U, Rautenstrauch J, Specker C, Schneider M (2017) Memorandum of the German Society for Rheumatology on the quality of treatment in rheumatology - update 2016. Z Rheumatol 76(3):195-207. https://doi.org/10.1007/s00393-017-0297-1

38. Benhamou M, Rincheval N, Roy C, Foltz V, Rozenberg S, Sibilia J, Schaeverbeke T, Bourgeois P, Ravaud P, Fautrel B (2009) The gap between practice and guidelines in the choice of first-line disease modifying antirheumatic drug in early rheumatoid arthritis: results from the ESPOIR cohort. J Rheumatol 36(5):934-942. https://doi.org/10.3899/jrheum.080762 